\title{
Functional Quality and Hedonic Quality: A Study of the Dimensions of e-Service Quality in Online Travel Agencies
}

\begin{abstract}
We attempted to clarify the dimensions of e-service quality and their role in producing perceived value and loyalty among customers of e-commerce websites. We particularly examined whether e-quality consisted of two groups of dimensions: (i) functional; or (ii) hedonic quality. Based on a survey of 1201 online customers of Spanish travel agencies, we $\backslash$ used structural equation modelling to show that both tpes of quality are distinct dimensions of e-quality and that both have positive and significant influence on perceived value. In addition, perceived value was shown to have a significant impact on loyalty, thus validating the chain from service quality-to-perceived value-to-loyalty in the context of e-commerce. The implication for e-service managers is that they must be aware of the importance of hedonic quality in seeking to attract and retain customers.

Keywords: e-quality, hedonic, perceived value, loyalty, travel agencies
\end{abstract}

\section{Introduction}

Today there is a need to clarify the dimensions of e-service quality and analyze their impact on perceived value and loyalty. Several dimensions of e-service quality have been suggested by the E-S-QUAL instrument [24] (efficiency, system availability, fulfilment, and privacy), and these dimensions have been further analysed. However, these four dimensions can all be described as functional quality dimensions rather than hedonic (which are primarily concerned with enjoyment and pleasure, rather than technical efficiency). In recent years, the importance of hedonic quality has been considered important by several authors. In particular, Heijden [15] can be considered analyzed the role of hedonics in websites and concluded that the hedonic nature of an IS was an important boundary condition for the validity of a technology acceptance model because perceived usefulness loses its dominant predictive value in favour of ease of use and enjoyment.

Given the apparent importance of hedonic quality in producing perceived value and loyalty, the aims of our study were threefold; to: .

1. analyse the potential of hedonic quality as a distinct dimension of e-service quality (in addition to the functional dimensions already included in scales such as E-S-QUAL). 
2. develop and assess a scale that incorporates items from both the functional scale and from the hedonic dimension; and.

3. assess the impact of e-quality (in terms of both functional and hedonic quality) on perceived value and loyalty in the context of online travel agencies.

\section{Literature review and conceptual model}

\subsection{Assessment of e-quality}

A variety of scales utilising various dimensions have been suggested for measuring service quality in the context of electronic commerce (e-service quality or e-quality). Many have focused on the quality of the website itself.

Parasuraman et al. acted on a wide view of e-service quality when they published two scales for assessing e-services - both adapted from the well-known SERVQUAL scale. This, which had originally been designed to assess quality in services in general, had been successfully adapted to a variety of sectors and contexts and had been adapted to the context of e-service quality.

The first of the two scales et al., was termed E-S-QUAL and included 22 items arranged in four dimensions: (i) efficiency (the ease and speed of accessing and using a website); (ii) fulfilment (the extent to which the sites promises of order delivery and item availability are fulfilled); (iii) system availability (the correct technical functioning of the site); and (iv) privacy (the degree to which the site is safe and protects customer information). The second scalewas termed the ERecS-QUAL; it was designed for conditions where customers had non-routine encounters with a sitea $\backslash$, such as attempted service recovery. Including 11 items arranged in three dimensions of: (i) responsiveness (effective handling of problems and returns); (ii) compensation (the degree to which the firm compensates customers who eperience problems); and (iii) contact (the degree of assistance through telephone or online representatives).

These two scales have subsequently been utilised and adapted in several empirical studies in various settings. Boshoff [5], who was one of the first to examine the relationship between equality and e-loyalty, proposed that the E-S-QUAL scale should have six dimensions rather than the original four. Marimon et al. [19], who applied the E-S-QUAL instrument to an analysis of the relationship between loyalty and purchasing in the context of an e-supermarket, expanded Boshoff's model. adding another construct. More recently, Fuentes-Blasco et al. [10] adapted items from the two scales in assessing service quality in an e-bank; in this setting, the authors confirmed the consequence chain from e-service quality to perceived value, and thence from perceived value to loyalty (e-loyalty). 
Given that most of these studies of e-quality and perceived value utilised adaptations of the dimensions of E-S-QUAL, which are essentially 'functional (rather than hedonic) in nature, the following hypothesis was proposed:

H1. The level of functional quality in a website is positively related to the level of perceived value.

\subsection{Hedonic quality}

Hedonic quality is defined as the value obtained by a consumer from finding and purchasing a particular good or service. Such quality can be distinguished from purely utilitarian (functional) quality. The impact of hedonic quality has received relatively little attention, especially in the online context. However, some more recent studies have examined aspects of these issues.

In general terms, differences in emotional experience do result in significantly different levels of word-of-mouth recommendation and repurchase intentions. Ahn et al. [1] examined whether the notion of playfulness (as a proxy for hedonic quality) played a role in technology acceptance (see also [8]). They found that playfulness had a significant positive effect on attitudes and intentions to use online retailing. Thus playfulness, together with other dimensions (such as ease of use, usefulness, and attitude), mediate the impact of web quality constructs on behavioural intention to use.

Hausman and Siekpe [14] assessed eight elements of potential importance for consumers' intentions to purchase and intention to return: (i) 'human factors; (ii) computer factors; (iii) usefulness; (iv) informativeness; (v) entertainment; (vi) irritation; (vii) attitude towards the site; and (viii) flow. They showed that all factors were important, although the effect of the first six was mediated indirectly through attitudes towards the site and flow. Moreover, flow was more important than attitude to the site in stimulating purchase and return intentions, and entertainment was the dimension that most explained flow. The authors concluded that these so-called hedonic dimensions should be cobsidered by website designs and marketers.

Vázquez-Casielles et al. [25] specifically introduced hedonic quality as a dimension of equality in their scale of e-service quality for travel agencies. Their results showed that responsiveness, reliability, and hedonic quality had the greqtest influence on customer satisfaction.

More recently, Yang et al. [13] proposed that hedonic quality should be included as another dimension of service quality in the E-S-QUAL scale. In testing this, they assessed: (i) the effects of service quality on online satisfaction and perceived value; and (ii) the consequent effects of online satisfaction and perceived value on loyalty. They showed that all direct relationships were 
significant, except that between perceived value and loyalty (although perceived value was found to have an indirect effect on loyalty through customer satisfaction). With respect to the servicequality construct, the most significant relationship was with perceived value, followed by customer satisfaction; the least significant was with loyalty. We therefore proposed the following hypothesis:

H2. The level of hedonic quality in a website is positively related to the level of perceived value.

Wakefield et al. [26] analysed how hedonic and technologic aspects (i.e., functional quality) affect the use of a website in different contexts. Website designers generally incorporate social cues, such as helpfulness and familiarity, into e-commerce sites. The social perceptions of websites lead to enjoyment and have a strong influence on user intention. Howevr, no evidence was found of a relationship between functional quality and hedonics. Previously, Heijden claimed that enjoyment and functional quality were determinants of intention to use. More specifically, Yang et al. proposed that hedonic quality should be included as another dimension of quality. On the other hand, we have no evidence of a causal relationship between functional quality and hedonic quality. Thus the following hypothesis was proposed:

H3. The level of functional quality in a website is positively correlated with hedonic quality.

\subsection{Relationship between perceived value and loyalty}

Fuentes-Blasco et al. found that perceived value has a direct and significant influence on loyalty to an e-shopping website (see also [9]). These authors also provided empirical evidence that the chain relationship from service quality-to-perceived value-to-loyalty $\backslash$ also applies in the online context. Gallarza and Gil [11] confirmed this chain in the context of tourism. Similar results in the mobile services sector have been reported by Lin and Wang [18].

Bauer et al. [4] argued that an hedonic dimension was necessary in the E-S-QUAL model for analysis of online customer behaviour, thus extending it to a five-dimension model (that they termed eTransQual). They concluded that all five dimensions had a significant positive impact on perceived value and customer satisfaction, thus highlighting the importance of enjoyment for a customer.

Boshoff] analysed the impact of e-quality on perceived value and loyalty using a sixdimensional model based on E-S-QUAL. His results showed that the proposed model fitted well and that the relationship between perceived value and loyalty was significant and strong. In a similar vein, Marimon et al. proposed a model linking the E-S-QUAL dimensions with perceived 
value, loyalty, and purchasing behaviour for an online supermarket. They found that the strongest relationship was that between perceived value and loyalty.

The following hypothesis was made:

H4. The level of perceived value in a website is positively related to the level of loyalty towards that website.

\subsection{The Conceptual model for Our study}

The four hypotheses are depicted diagrammatically in the conceptual model for the study (see Fig. 1). These relationships were tested in an empirical study.

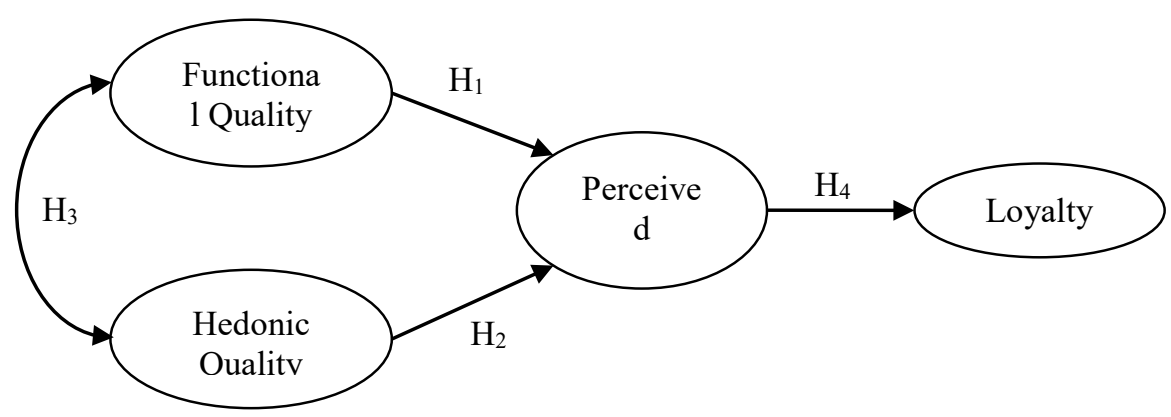

Fig. 1. Conceptual model and hypothesised relationships

\section{Methodology}

Data were collected through a structured questionnaire administered by telephone to the general public in Spain. A specialised company was in charge of the field work. The only required criterion for inclusion in the survey was that the respondents had to be consumers of online travel agencies.

Travel agencies were selected for this study for several reasons. First, according to ONTSI [21], 84.1\% of all tourism products (such as accommodation and transport) are purchased online. This is by far the largest proportion of e-commerce sales in any sector in Spain, with leisure products (36.5\% sold online) being the next most common. Secondly, the average expenditure on each tourism product is high (1,014 euros per purchase). Finally, $58.7 \%$ of e-shoppers are considered constant; having purchased via the Internet for two consecutive years and intending to continue to do so in the future.

The questionnaire was based on an extensive review of the relevant literature' it had five sections. The first, which was used to measure e-service quality, was an adaptation of the original 
E-S-QUAL scale for use in online travel agencies. The second assessed hedonic quality. The third and fourth assessed perceived value and loyalty, respectively. The fifth collected demographic data from the respondent.

In accordance with Akinci et al. [2], some items of the original E-S-QUAL scale were removed in the first section of the questionnaire. In the other sections, certain items were removed from those suggested in the original reference material. A panel of experts assessed the appropriateness of removing or rewriting some of these original items in order to adapt them to our context. A small pilot test was then undertaken to check the proposed items in the whole questionnaire. This process yielded 30 items. As shown in Table 1, these 30 items were arranged in four constructs:

- e-service quality: measured in accordance with E-S-QUAL as four dimensions: (i) efficiency (six items); (ii) system availability (two items); (iii) fulfilment (six items); and (iv) privacy (three items);

- hedonic quality: proposed initially as a separate construct (for our study) and measured by five items;

- perceived value: five items; and

- loyalty: three items.

Table 1 Questionnaire items and sources

\begin{tabular}{ll}
\hline Dimensions & Items \\
\hline Efficiency & EFF1: This site makes it easy to find what I need \\
& EFF2: It is easy to navigate on this site \\
& EFF3: This site enables me to complete a transaction quickly \\
& EFF4: Information on this site is well presented \\
& EFF5: The pages load quickly on this site \\
& EFF6: It is easy to get on to this site quickly \\
& SYA1: This site is always available for business \\
System & SYA2: This site does not crash \\
Fulfillabilityent & FUL1: This site makes items available for delivery within a suitable time frame \\
& FUL2: This site delivers the items ordered \\
& FUL3: This site has in stock the items the company claims to have \\
& FUL4: This site is truthful about its offerings \\
& FUL5: This site allows reservation changes and cancellations \\
& FUL6: All services to individual customers (invoices, promotions, etc.) are available \\
& PRI1: This site protects information about my online shopping behaviour. \\
& PRI2: This site does not share my personal information with other sites. \\
\hline Privacy &
\end{tabular}




\begin{tabular}{ll}
\hline & PRI3: This site protects information about my credit card. \\
Hedonic & HED1: I enjoy the multimedia information, suggestions, and recommendations provided \\
quality & to the customer on this website. \\
& HED2: I think it is great fun to browse this site. \\
& HED3: When interacting with this site, I do not realise how much time has elapsed. \\
& HED4: I enjoy sharing comments and experiences from other travellers. \\
& HED5: I really enjoy shopping at this website of the travel agency \\
Perceived & PEV1: The prices of the products and services available at this site are economical. \\
value & PEV2: Overall, using this site is convenient. \\
& PEV3: This site gives me a feeling of being in control. \\
& PEV4: Overall, this site gives me value for my money and effort. \\
PEV5: The experience of this site has satisfied my needs and wants \\
LOyalty
\end{tabular}$\quad \begin{aligned} & \text { LOY }: \text { I encourage friends and relatives to do business with this site. } \\
& \text { intentions }\end{aligned}$

All items were presented as statements to which respondents indicated their agreement/disagreement on a five-point Likert-type scale (from $1=$ strongly disagree; to $5=$ strongly agree).

The field work was completed in July 2010. After discarding some incomplete questionnaires, 1,201 valid completed questionnaires remained for analysis. The demographicsof the sample are shown in Table 2. No gender bias was detected. The majority (55.8\%) of the respondents were aged less than 35 years. The educational level of the sample was high, with two-thirds of respondents having a university degree. The average number of purchases made by each respondent from online travel agencies in the preceding year was 3.09. Respondents had spent an average of 904. Euros with online travel agencies in the preceding year. Each respondent therefore spent an average of 292 Euros on each purchase in that year. Respondents had been purchasing these services on the Internet for an average of 4.46 years.

The three websites most used by respondents represent $40.9 \%$ of the sites used in the first semester of 2010: 15.7\% of them bought from "edreams.com", 13.7\% from "atrapalo.com", and $11.5 \%$ from "rumbo.com". A total of 20 different websites were identified as having been used by the respondents.

Table 2 Demographic characteristics of sample

\begin{tabular}{llll}
\hline & & Number & $\%$ \\
\hline Age & Between 18 and 25 years & 304 & 25.3
\end{tabular}




\begin{tabular}{llll} 
& Between 26 and 35 years & 366 & 30.5 \\
& Between 36 and 45 years & 361 & 30.1 \\
& $>45$ years & 170 & 14.2 \\
Gotal & 1,201 & 100.0 \\
Male & 598 & 49.8 \\
Education & Female & 603 & 50.2 \\
& Total & 1,201 & 100.0 \\
& High school diploma & 183 & 15.2 \\
& Vocational qualification & 231 & 19.2 \\
& University degree & 767 & 63.9 \\
Annual income (euros) & Others & 20 & 1.7 \\
& Total & 1,201 & 100.0 \\
& Between 10,000 and 30,000 & 543 & 16.4 \\
& Between 30,000 and 50,000 & 201 & 45.2 \\
& Between 50,000 and 70,000 & 50 & 16.7 \\
& $>50,000$ & 27 & 4.2 \\
& I prefer not to answer & 183 & 2.2 \\
Total & 1,201 & 15.2 \\
\hline
\end{tabular}

\section{Results}

The data was analyzed in two stages: (i) assessment of the reliability, dimensionality, and validity of the measurement scale; and (ii) analysis of the causal relationships using SEM.

\subsection{Assessment of scales}

Exploratory factor analysis of the items of e-quality and hedonic quality (as listed in Table 1) revealed a Kaiser-Meyer-Olkin (KMO) value of 0.965 (which was greater than the recommended value of 0.7$)$. Bartlett's test of sphericity test was $8,260(\mathrm{df}=231)$ with a significance of 0.000 . These results confirmed a linear dependence between the variables and supported our view that the results were sound.

The scale was analysed in accordance with the recommendations of Ladhari [17]m who . followed the criteria proposed by Wolfinberger and Gilly [28] to retain items which: (i) load at 0.50 or more on a factor, (ii) do not load at more than 0.50 in two factors, and (iii) have an item to total correlation of more than 0.40 . In fact, we were more rigorous, raising the threshold of the 
load to 0.70 for the first criterion. We were also stricter with the second criterion; dropping items with load more than 0.40 in two factors (see Table 3).

Table 3 Measurement model (reliability and validity of scales)

\begin{tabular}{|c|c|c|c|c|c|c|}
\hline \multirow[b]{2}{*}{$\begin{array}{l}\text { Note: Please do not use more } \\
\text { than the number os significant } \\
\text { figures that are sensible ith } \\
\text { your data } \rightarrow \text { Tvalues should } \\
\text { be at most } 3 \text { figures, Please } \\
\text { consider carefully whether } \\
\text { three figures is meaningful for } \\
\text { your ue of Likert scales and } \\
\text { adjust the numbers } \\
\text { accordingly }\end{array}$} & \multicolumn{2}{|c|}{ First EFA (loadings) ${ }^{(*)}$} & \multicolumn{4}{|c|}{ CFA (Confirmatory Factory Analysis) } \\
\hline & $\begin{array}{l}\text { 'Functional } \\
\text { quality }\end{array}$ & Hedonics & $\begin{array}{l}\text { Standardized } \\
\text { loadings }{ }^{(* *)}\end{array}$ & $\begin{array}{l}\mathrm{t}- \\
\text { values }\end{array}$ & $r^{2}$ & \\
\hline Eff1 & 0.839 & & 0.807 & & 0.651 & Functional \\
\hline Eff2 & 0.821 & & 0.814 & 29.38 & 0.662 & Quality \\
\hline Eff3 & 0.794 & & 0.819 & 30.80 & 0.671 & Cronbach's \\
\hline Eff4 & 0.758 & & 0.780 & 28.32 & 0.608 & alpha: 0.938 \\
\hline Eff5 & 0.746 & & 0.782 & 25.56 & 0.612 & Range for \\
\hline Eff6 & 0.830 & & 0.800 & 22.75 & 0.640 & Cronbach's \\
\hline Syal & 0.778 & & 0.760 & 23.15 & 0.577 & alpha \\
\hline Sya2 & 0.523 & & & & & removing one \\
\hline Ful1 & 0.839 & & 0.791 & 21.84 & 0.626 & item: 0.930 - \\
\hline Ful2 & 0.805 & & 0.804 & 26.26 & 0.647 & 0.933 \\
\hline Ful3 & 0.563 & 0.470 & & & & Range for \\
\hline Ful4 & 0.649 & 0.413 & & & & $\begin{array}{l}\text { correlations } \\
\text { of the items } \\
\text { and the sum } \\
\text { of the } \\
\text { subscale: } \\
0.733-0.793 \\
\text { Average } \\
\text { variance } \\
\text { extracted } \\
\text { (AVE): } 0.663 \\
\text { Composite } \\
\text { reliability: } \\
0.946\end{array}$ \\
\hline Ful5 & & 0.688 & & & & \\
\hline Ful6 & 0.405 & 0.697 & & & & \\
\hline Pri1 & 0.553 & 0.556 & & & & Hedonic \\
\hline Pri2 & & & & & & Quality \\
\hline
\end{tabular}


Pri3
Hed1
Hed2
Hed3
Hed4
Hed5

0.572

0.441

Cronbach's

0.843

0.749

$0.832 \quad 0.864$

$0.785 \quad 0.801$

$0.785 \quad 0.655$

0.786

0.806

27.88

0.562 alpha: 0.938

0.746 Range for

26.450 .641 Cronbach's

Hed5

$0.786 \quad 0.806$

$21.29 \quad 0.428 \quad$ alpha

25.780 .649 removing one

item: 0.929 -

0.932

Range for

correlations

of the items

and the sum

of the

subscale:

$0.733-0.793$

Average

variance

extracted

(AVE): 0.663

Composite

reliability:

0.907

Second EFA (loadings)

\begin{tabular}{|c|c|c|c|c|c|}
\hline PeV1 & 0.722 & 0.648 & & 0.420 & Perceived \\
\hline PeV2 & 0.843 & 0.809 & 19.14 & 0.654 & Value \\
\hline PeV3 & 0.782 & 0.747 & 17.25 & 0.558 & Cronbach's \\
\hline PeV4 & 0.843 & 0.780 & 22.02 & 0.609 & alpha: 0.867 \\
\hline \multirow[t]{17}{*}{ PeV5 } & 0.856 & 0.841 & 20.40 & 0.707 & Range for \\
\hline & & & & & Cronbach's \\
\hline & & & & & alpha \\
\hline & & & & & removing one \\
\hline & & & & & item: 0.824 - \\
\hline & & & & & 0.866 \\
\hline & & & & & Range for \\
\hline & & & & & correlations \\
\hline & & & & & of the items \\
\hline & & & & & and the sum \\
\hline & & & & & of the \\
\hline & & & & & subscale: \\
\hline & & & & & $0.586-0.751$ \\
\hline & & & & & Average \\
\hline & & & & & variance \\
\hline & & & & & extracted \\
\hline & & & & & (AVE): 0.653 \\
\hline
\end{tabular}


Third EFA (loadings)

\begin{tabular}{|c|c|c|c|c|c|}
\hline Loy1 & 0.852 & 0.683 & & 0.467 & Loyalty \\
\hline Loy2 & 0.872 & 0.713 & 24.98 & 0.508 & Cronbach's \\
\hline \multirow[t]{21}{*}{ Loy3 } & 0.780 & 0.807 & 20.27 & 0.651 & alpha: 0.781 \\
\hline & & & & & Range for \\
\hline & & & & & Cronbach's \\
\hline & & & & & alpha \\
\hline & & & & & removing one \\
\hline & & & & & item: 0.629 - \\
\hline & & & & & 0.785 \\
\hline & & & & & Range for \\
\hline & & & & & correlations \\
\hline & & & & & of the items \\
\hline & & & & & and the sum \\
\hline & & & & & of the \\
\hline & & & & & subscale: \\
\hline & & & & & $0.545-0.684$ \\
\hline & & & & & Average \\
\hline & & & & & variance \\
\hline & & & & & extracted \\
\hline & & & & & (AVE): 0.681 \\
\hline & & & & & Composite \\
\hline & & & & & reliability: \\
\hline & & & & & 0.856 \\
\hline
\end{tabular}

EFA: Exploratory Factor Analysis

CFA: Confirmatory Factory Analysis

(*) cells in blank are loads below 0.4

$(* *)$ all significant at $\mathrm{p}$-value $=0.01$

Two factors, which accounted for $64.9 \%$ of the variance in the sample, were identified (see Table 3). The first, which was labelled functional quality gathered: (i) all six items of efficiency from Table 1; (ii) the first two items of fulfilment from Table 1; and (iii) the first item of system availability from Table 1. All of these came from the original E-S-QUAL scale. The second factor, which consisted of all five hedonic quality items from Table 1, was labelled hedonics. The differentiation of these two factors suggests that functional quality and hedonics are independent constructs. Table 3 shows this first exploratory factor analysis together with two morel.

A second exploratory factor analysis was then conducted on the items of perceived value (in Table 1$)$. The KMO index was satisfactory $(0.860)$, as was the Bartlett test of 2,65 $0(\mathrm{df}=10)$ 
with a significance of 0.000 (see Table 3). Only one factor with an eigenvalue greater than 1 appeared, explaining $65.7 \%$ of the variance.

A third exploratory analysis was performed on the three items of loyalty from Table 1 . These loaded on one factor that explained $70 . \%$ of the variance. The KMO measure was 0.680 and the Bartlett test was $979(\mathrm{df}=3)$ with a significance of 0.000 . Unidimensionality of all four scales was thus established. zzz

The reliability of these four factors was then assessed. Cronbach's alpha coefficient and composite reliability in every case exceeded the threshold value of 0.7 for internal consistency. In addition, the variance extracted for each scale was greater than 0.5 . These indices, as shown in Table 3, were acceptable for all factors.

Convergent validity was confirmed for all scales where all variables were shown to have significant weighting $(t>2.58)$. Discriminant validity was analysed by linear correlations or standardised covariances between latent factors by examining whether inter-factor correlations were less than the square root of the average variance extracted (AVE). Table 4 shows that the square roots of each AVE were greater than the off-diagonal elements. Discriminant validity was guaranteed; though the average variance extracted from perceived value was very similar to their correlation to loyalty.

Table 4 Correlation matrix of latent factors

Please confirm that four figure accuracy is justified with your data accuracy and sample size OR fic it to three figures

\begin{tabular}{lllll}
\hline & 1 & 2 & 3 & 4 \\
\hline 1 Functional quality & 0.8140 & & & \\
2 Hedonics & 0.4418 & 0.8144 & & \\
3 Perceived Value & 0.6123 & 0.5310 & 0.8081 & \\
4 Loyalty & 0.5678 & 0.5181 & 0.7978 & 0.8251 \\
\hline
\end{tabular}

Diagonal elements are the square roots of average extracted (AVE)

\subsection{Causal model}

In the external model we used latent constructs with reflective indicators. In fact, e-quality, ehedonics, perceived value, and loyalty evince and display the latent construct that encompasses them. Since these indicators are manifestations of the construct, we therefore use reflective construct items. 
The measurement model was estimated by using the robust maximum likelihood method from the asymptotic variance-covariance matrix. EQS 6.1. The fit indices obtained in the measurement model estimation showed that the variables converged towards the factors established in the CFA (see Table 5). $\chi^{2}$ Satorra-Bentler was 750, with 205 degrees of freedom and a $p$-value of 0.000. $\chi^{2} / \mathrm{df}$ was 3.67 , which was below the acceptable limit of 5 , RMSEA was 0.054 and the CFI was 0.924. Taking the significance of the robust $\chi^{2}$ statistic with caution, and noting the global indicators, the global fit was acceptable.

All four hypotheses were confirmed at a confidence level of $99 \%$. The results showed that higher levels of functional quality and hedonics were positively related to higher levels of perceived value, thus confirming $\mathrm{H} 1$ and $\mathrm{H} 2$. In addition, the results showed that functional quality and hedonics were positively correlated, thus confirming H3. Finally, the levels of perceived value were positively related to the levels of loyalty to he website, thus confirming H4.

Table 5 Standardized solution of the causal model

Please fix the numbers of sig. figs.!

\begin{tabular}{llll}
\hline & & Coefficient & t-value \\
& & $(*)$ & \\
\hline Path & Functional Quality $\rightarrow$ Perceived value & 0.498 & 7.835 \\
& Hedonics $\rightarrow$ Perceived value & 0.369 & 8.082 \\
& Perceived value $\rightarrow$ Loyalty & 0.957 & 16.486 \\
Correlation & Functional Quality and Hedonics & 0.482 & 9.743 \\
\hline (*) all significant at p-value $=0.01$ & &
\end{tabular}

Fit statistics: $\chi^{2}$ Satorra-Bentler $(\mathrm{df}=205)=752.44$ (p-value=0.000); RMSEA=0.054; CFI=0.924; BB-NFI=0.898; BB$\mathrm{NNFI}=0.914$

\section{Discussion}

Although both functional quality and hedonics had a positive impact on perceived value, the two paths were not equivalent. It is apparent that functional quality had a greater impact on perceived value than did hedonics. These findings are in accordance with other studies, such as [16]. Moreover, if the dimensions of functional quality and hedonics are taken to represent dimensions of overall e-quality, the results are in accordance with other studies that have examined similar dimensions and their relationships with perceived quality.

Our results are also in general accordance with Bauer et al.. However, it should be noted that our study obtained only two factors for e-quality - one representing the original E-S-Qual dimensions (functional quality) and the other representing hedonic quality (hedonics). 
With regard to the positive correlation between functional quality and hedonics (H3), our finding reinforces the addition of an hedonic quality dimension onto the original scale. As previous studies have shown, hedonic quality (such as playfulness) has a significant positive effect on individuals attitudes and intentions to use online retailing.

Finally, our finding that levels of perceived value in a website were positively and strongly related to levels of loyalty with respect to that website (H4) is in accordance with several studies with similar findings. Nevertheless, the interpretation of this finding must be used with caution due to the detected lack of discriminant validity between perceived value and loyalty.

It is also noteworthy that the present study confirms the findings on Gallarza and Gil ([2]), who investigated the same sector.

\section{Conclusions}

Three main conclusions can be drawn from our study. First, hedonic quality is an intrinsic dimension of e-quality. As a consequence, e-quality should be assessed in terms of two distinct dimensions: (i) functional; and (ii) hedonic quality. A related conclusion is that the functional dimension represents three out of the four E-S-Qual dimensions (the privacy dimension from the original E-S-Qual has been dropped completely), with the present study's dimension of hedonics representing an additional dimension. It is also apparent that both functional quality and hedonics contribute to perceived value, although functional quality makes a greater contribution. It should be emphasised, however, that what is really important is functional quality. Nevertheless, our findings provide practitioners with factors to consider when choosing projects in which to invest. Improving efficiency results in a major impact on loyalty, but we should include the amount of money invested to obtain a ratio showing the impact on loyalty per euro invested.

Secondly, our study has found evidence that the chain from e-quality $\rightarrow$ perceived value loyalty is significant in the context of tourism e-commerce.

Thirdly, the results have implications for website design and business strategy. On the one hand when travel agencies design their e-commerce sites, they must be aware that their customers are not only hoping to achieve their goals in terms of making an appropriate purchase, but also seeking to enjoy the experience of purchasing. To that end, companies should study the customers web use behaviour and foster hedonic functionalities.

On the other hand, Wallet [27] found that almost half of the users had a specific website in mind when they search for information or make a transaction. Linking this finding with our results, both suggest that when functional quality is achieved, the hedonic dimension becomes 
relevant in order to differentiate a website. In others words, the hedonic dimension could contribute to creating a competitive advantage and to maintaining a sustainable Internet business, so that the hedonic dimension should be a key dimension in the building of a company in terms of e-commerce strategy. Although our findings reinforce the importance of the hedonic dimension, more research is needed to assess its economic implications. Therefore, understanding the role of the hedonic dimension in the e-commerce context will be a priority line of research in future.

The main limitation of the study, as in most empirical studies, is the size and breadth of the sample. Future work is not discussed in $\mathrm{I}^{\wedge} \mathrm{M}$ pblished papers

Another limitation of this research is in the geographical origin of the sample. Other papers have been published taking samples from different geographical areas, but it is difficult to establish comparisons between them. In relation to this aspectAlso, no information about travel agents was gathered, and having both visions of the service could have enriched our study. A minor limitation is the lack of discriminant validity between perceived value and loyalty. More research should be carried out. However, this does not compromise the analysis of the relative importance between functional quality and hedonic quality.

\section{Acknowledgment}

This study is part of a larger research project entitled "Customers satisfaction improvement in Spanish organizations through standardization" (ECO2009-12754-CO2-01), which is financed by the Ministry of Science and Innovation within its aid programme for research \& development projects.

\section{References}

[1] T. Ahn, S. Ryu, I. Han. The impact of Web quality and playfulness on user acceptance of online retailing, Information and Management 44 (3), 2007, pp. 263275.

[2] S. Akinci, E. Atilgan-Ina., S. Aksoy. Re-assessment of E-S-Qual and E RecS-Qual in a pure service setting, Journal of Business Research 63, 2010, pp. 232-240

[3] S. Barnes, R. Vidgen. An integrative approach to the assessment of e-commerce quality, Journal of Electronic Commerce Research 3 (3), 2002, pp. 114-127. 
[4] H. Bauer, T. Falk, M. Hammerschmidt. eTransQual: a transactiona process-based approach for capturing service quality in online shopping, Journal of Business Research 59 (7), 2006, pp. 866-875.

[5] C. Boshoff. A psychometric assessment of E-S-QUAL: A scale to measure electronic service quality. Journal of Electronic Commerce Research 8 (1), 2007, pp. 101-115.

[7] R. Chitturi, R. Raghunathan, V. MahajanDelight by design: the role of hedonic versus utilitarian benefits, Journal of Marketing 72 (3), 2008, pp. 48-63.

[8] J. Chung, F. Tan. Antecedents of playfulness: an exploratory study on user acceptance of general information-searching websites, Information and Management 41 (7), 2004, pp. 869-881.

[9] S. Forsythe, C. Liu, D. Shannon, L. Gardner. Development of a scale to measure the perceived benefits and risks of online shopping, Journal of Interactive Marketing 20 (2), 2006, pp. 55-75

[10] M. Fuentes-Blasco, I. Gil-Saura, G. Berenguer-Contrí, B. Moliner-Velázquez. Measuring the antecedents of e-loyalty and the effect of switching costs on website, The Service Industries Journal 30 (11), 2010, pp. 1837-1852.

[11] M. Gallarza, I. Gil. Value dimensions, perceived value, satisfaction and loyalty: an investigation of university students' travel behaviour, Tourism Management 27 (3), 2006, pp. 437-452.

[12] R. Hair, R. Anderson, R. Tatham, W. Black. Multivariate data analysis. 5th ed., Upper Saddle River: Prentice Hall International, 1998.

[13] H.-E. Yang, W.-J. Cheng, J.-Y. Chan, B.-C. Pan, and C.-S. Chia. Applying an extended ES-Qaul Scale to assess the effects of e-service quality on online loyalty with customer satisfaction and perceived value as mediators, Proceedings of the $9^{\text {th }}$ WSEAS Int. Conference on Applied Computer and Applied Computational Science, Hangzhow, China, 2010, pp. 55-59.

[14] A. Hausman, J. Siekpe. The effect of web interface features on consumer online purchase intentions, Journal of Business Research 62 (1), 2009, pp. 5-13.

[15] H. Heijden. User acceptance of hedonic information systems, MIS Quarterly and The Society for Information Management 28(4), 2004, pp. 695-704.

[16] C. Ho, Y. Lee. The development of an e-travel service quality scale, Tourism Management 28 (6), 2007, pp.1434-1449.

[17] R. Ladhari. Developing e-service quality scales: A literature review, Journal of Retailing and Consumer Services 17, 2010, pp. 464-477 
[18] H. Lin, Y. Wang. An examination of the determinants of customer loyalty in mobile commerce contexts, Information and Management 43 (3), 2006, pp. 271-282

[19] F. Marimon, R. Vidgen, S. Barnes, E. Cristobal. Purchasing behaviour in an online supermarket: the applicability of E-S-QUAL, International Journal of Market Research 52 (1), 2010, pp. 111-129.

[20] J. Moon, Y. Kim. Extending the TAM for a World-Wide-Web context. Information and Management, 38 (4), 2001, pp. 217-230.

[21] ONTSI. Estudio sobre el Comercio Electrónico B2C 2008. Observatorio Nacional de las Comunicaciones y de la SI. (Study on B2C e-Commerce 2008. National Observatory of Communications and Information Society). Available in www.red.es Revised in Nov, 9, 2010

[22] A. Parasuraman, D. Grewal. The impact of technology on the quality-value-loyalty chain: A research agenda, Journal of the Academy of Marketing Science 28 (1), 2000, pp. 168-174.

[23] A. Parasuraman, V. Zeithaml, L. Berry. SERVQUAL: A multiple-item scale for measuring consumer perceptions of service quality, Journal of Retailing 64 (1), 1988, pp. 12-40.

[24] A. Parasuraman, V. Zeithaml, A. Malhotra. A multiple-item scale for assessing electronic service quality, Journal of Service Research 7 (3), 2005, pp. 213-233.

[25] R. Vázquez-Casielles, A. del Río-Lanza, L. Suárez-Álvarez. Las agencias de viaje virtuales: ¿Cómo analizar la calidad de e-servicio y sus efectos sobre la satisfacción del cliente?, (Virtual travel agencies: how to analyze the e-service quality and its effects on customer's satisfaction?) Universia Business Review Cuarto Trimestre (Fourth Quarter) 24, 2009, pp. 122-143.

[26] R. Wakefield, J. Baker, L. Wang. How Website Socialness Leads to Website Use, European Journal of Information Systems 20, 2011, pp. 118-132.

[27] V. Waller. Not Just Information: Who Searches for What on the Search Engine Google?, Journal of the American Society for Information Science and Technology 62 (4), 2011, pp. 761775 .

[28] M. Wolfinberger, M. Gilly. eTailQ: dimensionalizing, measuring and predicting etail quality, Journal of Retailing 79, 2003, pp. 183-198.

[29] B. Yoo, N. Donthu. Developing a scale to measure the perceived quality of an internet shopping site (SITEQUAL), Quarterly Journal of Electronic Commerce 2 (1), 2001, pp. 31-47.

[30] V. Zeithaml, A. Parasuraman, A. Malhotra. A conceptual framework for understanding eservice quality: Implications for future research and managerial practice. Cambridge: Marketing Science Institute, 2000. 